\title{
Reimplantation of a tricuspid valve bioprosthesis due to its thrombosis and recurrence of infective endocarditis
}

\author{
Anna Olasińska-Wiśniewska, Bartłomiej Perek, Sławomir Katarzyński, \\ Hanna Wachowiak-Baszyńska, Paweł Marcinkowski, Marcin Ligowski, Marek Jemielity \\ Department of Cardiac Surgery and Transplantology, Poznan University of Medical Sciences, Poznań, Poland
}

Correspondence to: Anna Olasińska-Wiśniewska, MD, PhD, Department of Cardiac Surgery and Transplantology, ul. Długa1/2, 61-848 Poznań, Poland, phone: +48618549210 , email: annaolasinska@ump.edu.pl Received: September 16, 2020. Revision accepted: November 2, 2020. Published online: November 13, 2020. Kardiol Pol. 2021; 79 (1): 83-84 doi:10.33963/KP.15682 Copyright by the Author(s), 2021
A 21-year-old woman, a former drug addict, was admitted for urgent cardiac surgery, presenting with severe heart failure (New York Heart Association functional class IV) due to tricuspid bioprosthesis dysfunction. Two months earlier in another hospital, she had undergone mitral valve replacement with a 25-mm Edwards Perimount valve (Edwards Lifesciences Corp., Irvine, California, United States) and tricuspid valve (TV) replacement with a $29-\mathrm{mm}$ Edwards Perimount valve (Edwards Lifesciences Corp.) due to methicillin-sensitive Staphylococcus aureus infective endocarditis. She was adequately treated with intravenous antibiotic therapy for 5 weeks following the surgery. International normalized ratio (INR) values were poorly controlled owing to lack of regular pharmacotherapy. Although the patient was treated with intravenous heparin, progressive deterioration was observed. Transthoracic (TTE) and transesophageal echocardiography demonstrated mitral periprosthetic leak and tricuspid prosthesis obstruction with a large thrombus impairing the motion of the leaflets (FIGURE 1A-1C; Supplementary material, Videos $S 1$ and $S 2$ ). Intraoperatively, debridement of the tricuspid bioprosthesis turned out to be impossible; therefore, bioprosthesis replacement was performed. Unfortunately, signs of persistent infection were also found. Macroscopically, tissues adjacent to the tricuspid valve were not completely healed. Moreover, an emptied abscess cavity was noted and debrided. A mitral paravalvular leak without local signs of active infection was sealed with 2 pledgetted 2-0 Ticron sutures. Antibiotic therapy was initiated.
Microbiological cultures of the explanted prothesis yielded negative results. In the postoperative period, a significant clinical improvement was achieved. However, on postoperative TTE, a small ventricular septal defect with an insignificant left-to-right shunt was detected and then confirmed by cardiac magnetic resonance imaging. The patient was discharged and referred to the rehabilitation hospital with a recommendation to present for regular checkups, which she unfortunately missed. The woman reported low INR values despite the use of increased oral anticoagulant doses, which most probably resulted from noncompliance to pharmacotherapy. However, she refused further hospitalization and was lost to contact.

Cardiac surgery is a rare option for the treatment of TV endocarditis. If necessary, repair is a preferred treatment of choice. Although several authors reported similar long-term survival rates after TV repair and replacement, longer freedom from recurrent IE and reoperation encourages the repair. ${ }^{1,2}$ It is strongly recommended that surgeons remove a vegetation and repair the valve whenever possible instead of implanting any artificial materials into the actively infected tissues. Additionally, thrombosis of TV prostheses occurs in $20 \%$ of cases $^{3}$ and may result from their thrombogenic surface, inadequate anticoagulation, numerous turbulences, and lower pressures on the right side, with slower transprosthetic flow. ${ }^{1,3}$ Of note, any kind of prosthesis should be particularly avoided when a history of drug abuse and labile INR is known, since recurrence is often observed. ${ }^{1,4,5}$ In our 

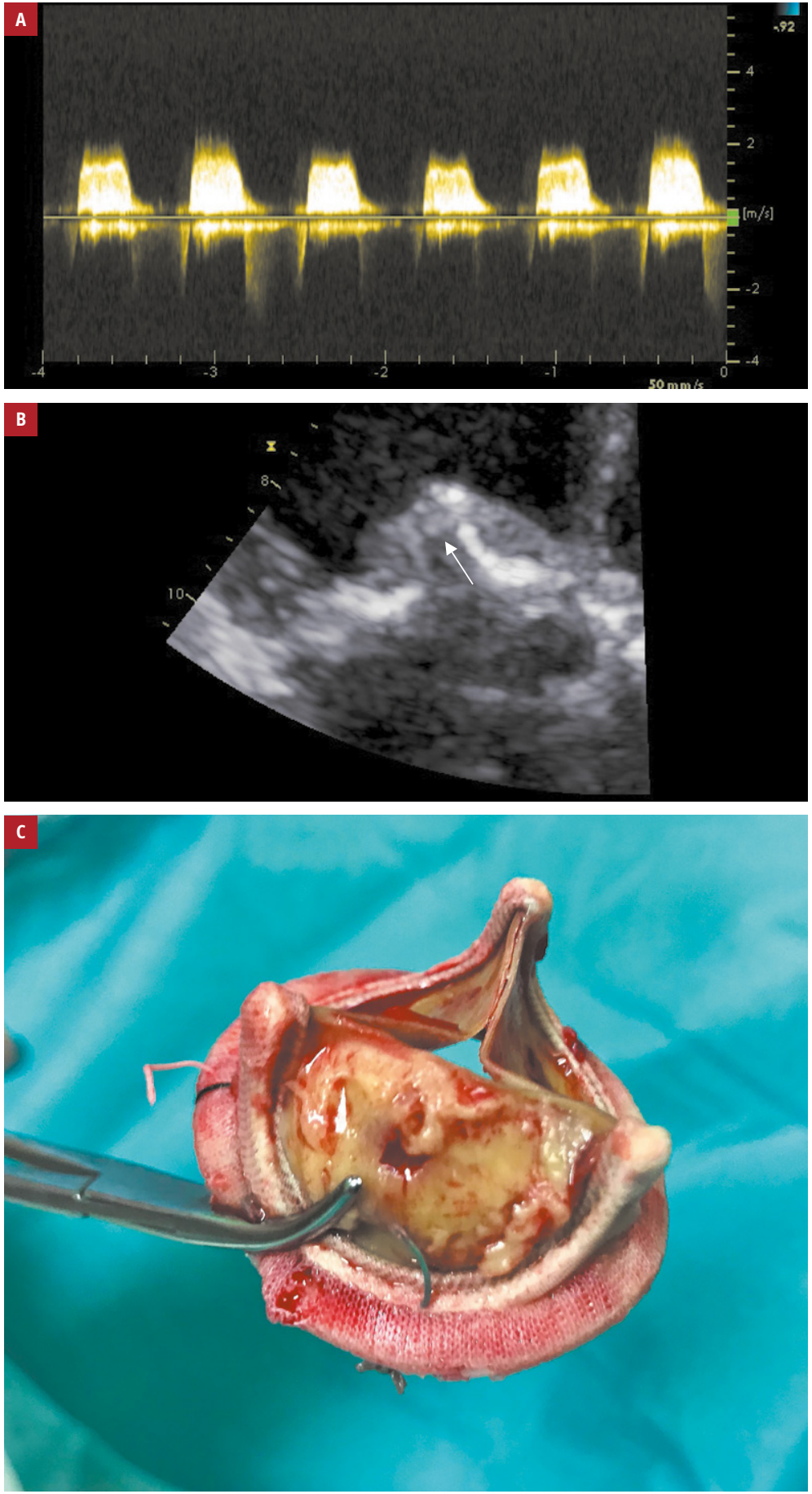

FIGURE 1 A - continuous transthoracic Doppler echocardiography showing a high transvalvular gradient caused by severe tricuspid prosthesis obstruction; B - transthoracic echocardiography demonstrating tricuspid prosthesis obstruction with a large thrombus (arrow) impairing the motion of the leaflets; $\mathbf{C}$ - intrasurgical view: the excised tricuspid valve bioprosthesis

patient's case, massive obstructive thrombosis resistant to high-dose heparin treatment prompted the decision to perform surgical reintervention. Moreover, previous valve replacement due to complete destruction of the remnants of the native TV forced the reimplantation of bioprosthesis during repeat surgery.

Ventricular septal defect found postoperatively in our patient was not visible on serial preoperative TTE. It could be caused by smoldering active infection (findings from reintervention) covered by one of the struts of the implanted, almost completely thrombosed bioprosthesis or hidden in turbulences of a severely stenotic TV. According to the current guidelines, patients with a history of endocarditis should undergo ventricular septal defect closure. In our patient, given the short time after the second cardiac surgery and the presence of an insignificant shunt, we decided to postpone the closure.

\section{SUPPLEMENTARY MATERIAL}

Supplementarwy material is available at www.mp.pl/kardiologiapolska.

\section{ARTICLE INFORMATION}

\section{CONFLICT OF INTEREST None declared.}

OPEN ACCESS This is an Open Access article distributed under the terms of the Creative Commons Attribution-NonCommercial-NoDerivatives $4.0 \mathrm{In}$ ternational License (CC BY-NC-ND 4.0), allowing third parties to download articles and share them with others, provided the original work is properly cited, not changed in any way, distributed under the same license, and used for noncommercial purposes only. For commercial use, please contact the journal office at kardiologiapolska@ptkardio.pl.

HOW TO CITE Olasińska-Wiśniewska A, Perek B, Katarzyński S, et al. Reimplantation of a tricuspid valve bioprosthesis due to its thrombosis and recurrence of infective endocarditis. Kardiol Pol. 2021; 79: 83-84. doi:10.33963/KP.15682

\section{REFERENCES}

1 Shmueli H, Thomas F, Flint N, et al. Right-sided infective endocarditis 2020: challenges and updates in diagnosis and treatment. J Am Heart Assoc. 2020; 9: 0017293.

2 Yanagawa B, Elbatarny M, Verma S, et al. Surgical management of tricuspid valve infective endocarditis: a systematic review and meta-analysis. Ann Thorac Surg. 2018; 106: 708-715

3 Caceres-Loriga FM, Perez-Lopez H, Santos-Gracia J, Morlans-Hernandez K. Prosthetic heart valve thrombosis: pathogenesis, diagnosis and management. Int J Cardiol. 2006; 110: 1-6.

4 Kupczyńska K, Lipiec P, Michalski BW, Kasprzak JD. Recurrent endocarditis causing severe obstruction of bioprosthetic tricuspid valve. Kardiol Pol. 2017; 75 : 182.

5 Brubert J, Cahill TJ, Prendergast BD. How to prevent infective endocarditis in 2020? Practical issues. Kardiol Pol. 2020; 78: 959-966. 